\title{
EVALUATION OF IMMEDIATE BASAL IMPLANTS PLACEMENT IN MAXILLARYPREMOLAR REGION
}

\author{
Shaymaa M. Warda ${ }^{*}$ BDS, Riham M. Eldibany² ${ }^{2 h D}$, Marwa G. Noureldin ${ }^{3 h h D}$
}

\begin{abstract}
INTRODUCTION: Dental implants have become an integral part of comprehensive management of dental patients. The clinical immediate replacement of lost teeth by osseointegrated implants have been one of the most significant advances in dentistry. Basal dental implants where developed for immediate use.

OBJECTIVES: This study was designed to evaluate immediate placement of basal dental implants in maxillary premolar region.

MATERIALS AND METHODS: Thirteen basal dental implants placed in ten adult patients having maxillary premolar tooth or remaining root indicated for extraction, all patients were operated under local anaesthesia, atraumatic extraction using a periotome was performed then the tooth was removed using the forceps, mesial and distal incisions were done, an osteotomy was done, the basal dental implant was placed then stability was measured by periotest, clinical evaluation and radiographic follow up using cone beam C.T ware done.

RESULTS: Thirteen implants were placed and followed up both clinically and radiographically for 6 months. In our study, the range of implant stability using periotest was -7.9 to +6.2 immediately, while after 6 months, the range of implant stability was -8.0 to +3.7 .

CONCLUSIONS: Basal dental implants are a reliable option for immediate placement after extraction of maxillary premolar teeth with good flap, suturing and reinforcing on maintaining good oral hygiene.

KEYWORDS: stability, maxilla, Immediate placed implants, Basal dental implants.

RUNNING TITLE: Immediate basal implants in maxillary premolar region.
\end{abstract}

1 Bachelor of Dentistry, Faculty of Dentistry, Alexandria University, Alexandria Egypt.

2 Professor of Oral and Maxillofacial Surgery, Faculty of Dentistry, Alexandria University, Alexandria Egypt.

3 Lecturer of Oral and Maxillofacial Surgery, Faculty of Dentistry, Alexandria University, Alexandria, Egypt.

*Corresponding author

E-mail: shaymaa.warda.87@gmail.com

\section{INTRODUCTION}

Dental implants have become an integral part of comprehensive management of dental patients. The clinical replacement of lost teeth by osseointegrated implants has been one of the most significant advances in dentistry. Osseointegration is the morphologic and functional coexistence between the bone and the surface of a loadcarrying implant (1).

Successful implant therapy often requires sound osseous support. Tooth loss always leads to atrophic changes of the alveolar ridge and the key processes of post extraction bone modeling and remodeling have been well documented in both animal and human studies (2).

Bone loss followed by tooth extraction may prevent dental implant placement, which encourages clinicians to carry out the immediate placement of dental implants into the extraction socket (3).

Immediate placement of a dental implant in an extraction socket has many advantages as cost and time saving, avoidance of additional surgical risks, preservation of the alveolar ridge at the site of extraction and adequate soft tissue esthetics (4).

Nonetheless, some complications associated with immediate implant placement were recorded; infection

arising during the first few post-operative days presented as edema, exudate and pain. This is caused by contamination during surgery (5). Also, dehiscence has been reported to occur and opening of the surgical wound edges exposing part or all of the implant head (6).

Lack of osseointegration and implant stability is one of the worst complications of immediate implant placement (7). Stability is the most important factor for the loading of an implant with prosthesis and for its success. In immediate implant cases, there is a customized socket wall for attaining good initial stability. To attain good initial stability/primary stability, implants $2 \mathrm{~mm}$ longer than the socket length are selected and excess preparation of $2 \mathrm{~mm}$ beyond the socket is performed, with initial drilling followed by sequential drilling. (8)

Therefore, the initial stability attained is primarily due to the contact of the implant-bone interface, only in the apical onethird. Selection of the implant body contour is very important to attain good initial stability. As the socket wall is tapered toward the apex, it is best to use cylindrical or screw shaped implants. (8)

Basal implantology, also known as bicortical implantology or just cortical implantology, is a modern implantology system which utilizes the basal cortical portion of the jaw bones for retention of the dental implants which are uniquely designed to be accommodated in the basal cortical bone areas. The basal bone provides excellent quality cortical bone for retention of these unique and highly advanced implants. Because basal implantology includes the application of the rules of orthopedic surgery, the basal 
implants are also called as "orthopedic implants" to mark a clear distinction between them and the well-known term "dental implants." These implants when placed in this bone can also be loaded with teeth immediately. (9)

Basal Implants are used in situations when multiple teeth are missing or have to be extracted, when a bone augmentation procedure has failed, cases of thin ridges (that is deficiency of bone in buccolingual thickness) and cases where bone height is insufficient.(10)

The basal implants are single piece implants in which the implant and the abutment are fused into one single piece. This minimizes the failure of implants due to interface problems, the connections which exists in conventional two and three piece implants. They have polished surfaces which stop bacteria and plaque from adhering to the implant neck or body. The thin implant body is combined with wide thread turns that enhances the vascularity around the implant and increases the bone implant contact. The abutment can be bent by 15 - 25 degrees depending upon the length of the implant, provided the implant is placed in dense corticated bone. (10)

Roott basal dental implants are one-piece implant for residual alveolar ridge atrophy with bendable neck and polished body. They are single component implants with wide range of sizes from short and wide to thin and long with short and long necks. Roott basal dental implants have diameter of 3.5 or $4.5 \mathrm{~mm}$ with shafts of 10 to $26 \mathrm{~mm}$ in length, also have diameter of 5.5 or $6.5 \mathrm{~mm}$ with shafts of 10 to $16 \mathrm{~mm}$ in length. They have Sharp threads allow anchorage in basal bone and with polished surface protects from accumulation of bacteria at the cervical part of the implant. (11)

This study aimed to evaluate clinically and radiographically the immediate placement of a new design of basal dental implants in the maxillary premolar region.

\section{MATERIALS AND METHODS}

A clinical trial was conducted on thirteen basal dental implants placed in ten adult patients having maxillary premolar area indicated for extraction and for implant rehabilitation. The patients were selected from the Out Patient Clinic of the Oral and Maxillofacial Surgery Department, Faculty of Dentistry, Alexandria University.

All patients were informed about basal dental implant placement procedure and they gave their approval to participate in this study with written consent. Ethical approval for this study was obtained from the research ethics committee, Faculty of Dentistry, Alexandria University before beginning the study.

The inclusion criteria for this research were age ranging from 26-40 years, good oral hygiene and presence of a maxillary premolar teeth indicated for extraction. The exclusion criteria were presence of acute infection, current chemotherapy or radiotherapy, heavy smokers and uncontrolled systemic diseases (diabetic, autoimmune diseases,etc).

\section{Materials}

\section{1) The implant system}

Basal dental implants (Roott basal dental implant, TRATE AG, Swizerland)

They are one piece basal dental implant (Figure 1) with Different lengths $(10,12) \mathrm{mm}$ and diameter $(3.5,4.5) \mathrm{mm}$. This implant has apical self- tapping blades and nontraumatic antirotation cuts with long polished/bendable neck. Moreover, basal dental implant has ergonomically designed abutment with round indicator and high-precision cone provides more accurate and aesthetic construction.

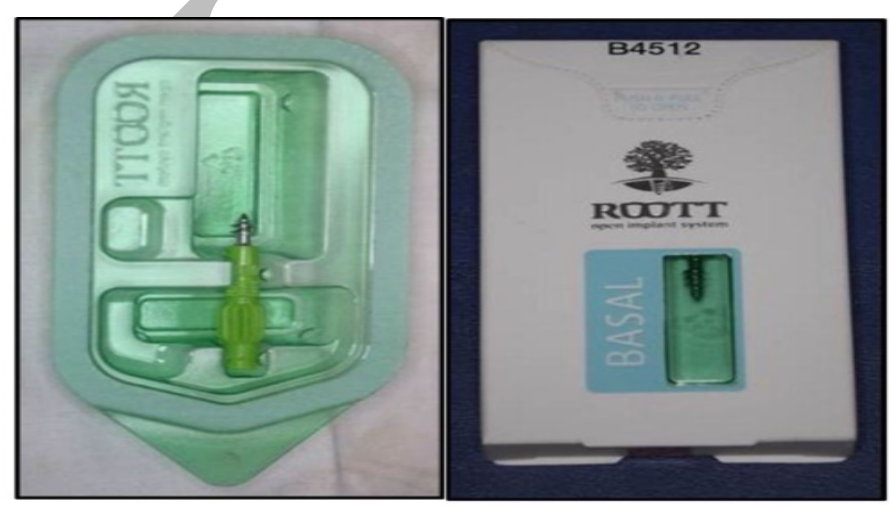

Figure (1): One piece basal dental implant.

2) Periotest M (Medizintechnik Gulden e. K. . . Eschenweg 3.64397 Modautal/Germany)Implant stability was measured using periotest. (12) The periotest measuring procedure is electro mechanical. An electrically driven and electronically monitored tapping head percusses the implant. The entire measuring procedure takes around 4 seconds. The tapping head has a pressure sensitive tip which records the duration of contact with the implant. Periotest value (PTV) is marked from -8 (low mobility) to +50 (high mobility). PTV of -8 to 6 is considered good stability.

\section{3) Periotome}

Atraumatic extraction using a periotome was performed. This instrument helped in removing firm teeth and remaining roots without damaging the surrounding thin alveolar plates of bone and minimally lacerating the soft tissue as well.

\section{Methods}

\section{Preoperative phase \\ 1. History \\ a) Personal history}

The data was collected and recorded in full details, including, name, age, address, telephone number.

\section{b) Past medical history and Past dental history}

A chart included past medical history, family history, drug history and past dental history was fulfilled.

\section{Clinical examination}

Inspection of tooth to be extracted, adjacent and opposing dentition, occlusion and soft tissue to detect any swelling or inflammation. Palpation for buccal and palatal mucosa at site of extraction.

\section{Radiographic examination}

Orthopantomogram (OPG) was obtained pre-operatively to ensure that the selected site is free from any local pathological radiolucent or radiopaque shadow in the 
working area and to evaluate the suitability of the patient regarding vertical bone height and pneumatization of the maxillary sinus.

Cone Beam Computed Tomography (CBCT) was performed to measure bone height and width, bone density and to determine the implant size. (Figure 2)

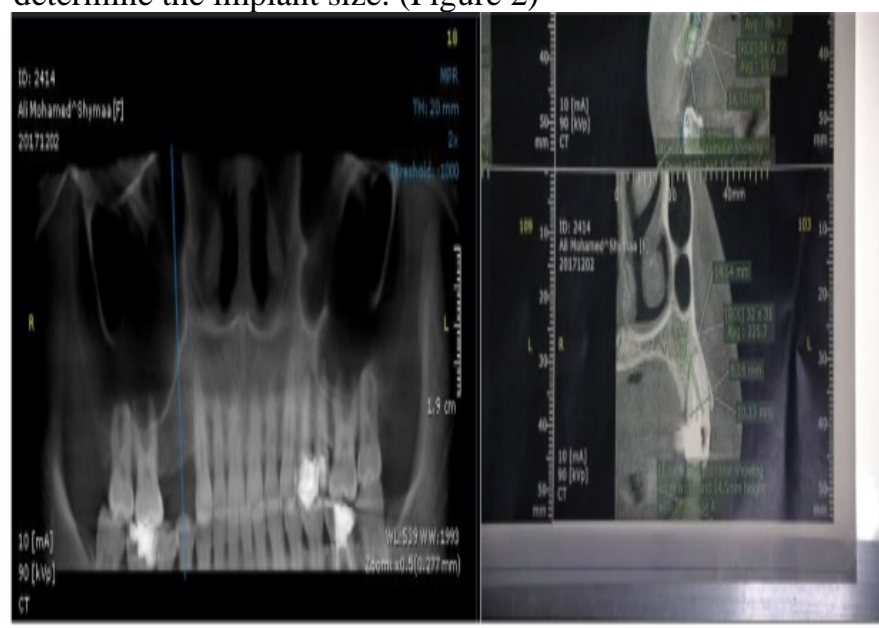

Figure (2): photograph showing Preoperative CBCT

\section{II- Surgical phase}

The oral cavity was disinfected by asking the patient to rinse using $0.12 \%$ chlorhexidine mouth rinse solution for 2 minutes before operation. All patients were operated under local anaesthesia using infiltration technique (mepivacaine HCL 2\% with levonordefrin 1:20000).

Atraumatic extraction using a periotome was performed. This instrument helped in removing firm tooth and remaining roots without damaging the surrounding thin alveolar plates of bone and minimally lacerating the soft tissue as well. Curettage and irrigation of the extraction socket using saline was performed.

Mesial and distal incisions were done using number 15 scalpel blade and the pyramidal mucoperiosteal flap was elevated. Flap was done to control soft tissue contour around implant. An osteotomy was done using the pilot drill for socket preparation and drilling to a depth of $3 \mathrm{~mm}$ beyond the socket. The basal dental implant (Roott basal dental implant, TRATE AG, Swizerland) was placed with hand pressure using the plastic cap and then using the ratchet wrench. Measurement of implant primary stability by the Periotest $\mathrm{M}$ was done. (Figure 3)

\section{Postoperative phase}

\section{Postoperative instructions}

All patients were instructed to apply cold packs intermittently for 24 hours. Patients were instructed not to bite on the implant. Sutures were removed one week postoperatively and the provisional acrylic restoration was delivered.

\section{Postoperative medication}

Antibiotic was prescribed to all patients: amoxicillin 875 mgs and clavulanic acid 125 mgs tablets (Augmentin 1g, GlaxoSmithKline, UK.) for 5 days every 12 hours. Nonsteroidal anti-inflammatory drugs NSAID also were prescribed to all patients: diclofenac potassium 50 mgs tablets (Cataflam, Novartis-Switzerland.) for 5 days every 8 hours. All patients were instructed to rinse with warm mouth wash starting on the next day for 2 weeks (chlorhexidine HCL $\quad 0.12 \%$, Hexitol: Chlorhexidine 125mg/100ml, concentration 0.125\%: Arabic drug company, Egypt.).

Follow- up phase

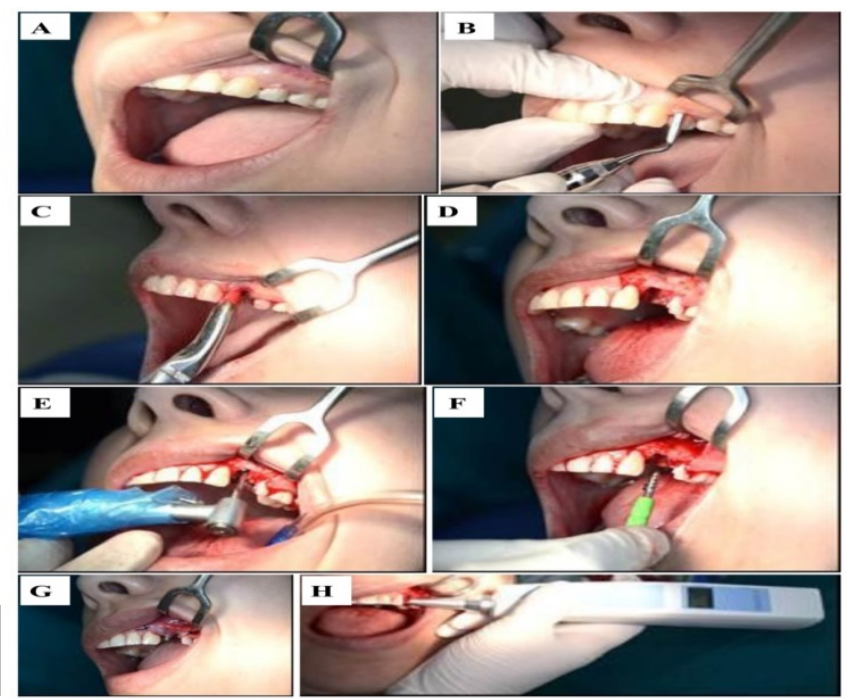

Figure (3): Photograph showing immediate placement technique

a. Photograph showing the tooth

b. Photograph showing atraumatic extraction using a periotome.

c. Photograph showing tooth extraction.

d. Photograph showing mucoperiosteal flap reflection.

e. Photograph showing initial drilling.

f. Photograph showing Implant insertion using the plastic cap manually

g. Photograph showing Suturing of the mucoperiosteal flap.

h. Photograph showing measurement of implant Primary stability by placing the Periotest

\section{a) Clinical evaluation}

1. Postoperative pain

All patients were evaluated daily for the first week then weekly for the first month regarding the presence of pain, tenderness and discomfort. Pain was evaluated through visual analogue scale (13): it is a horizontal line, $100 \mathrm{~mm}$ in length, anchored by word descriptor at each end. The patients mark on the line the point that they feel represents their prescription by measuring in millimeters from the left hand end of the line to the point that the patients mark. Tenderness and discomfort were evaluated according to the signs and symptoms of the patients. The category criteria for assessment were as follows:

$0=$ no pain

$1=$ mild pain: It is easily tolerated.

$2=$ moderated pain: It is causing discomfort but bearable.

$3=$ severe pain: It causing discomfort, hardly tolerated and unbearable.

\section{Implant stability}

Implant stability was measured immediately following implant insertion and after six months using Periotest $\mathrm{M}$. 


\section{b) Radiographic follow up}

All implants were examined radiographically immediately and after six months with cone beam computed tomography analysis to assess:

\section{Marginal bone level change (linear analysis)}

Mesial and distal bone height changes around the implants were evaluated using the linear measurements system supplied by Ondemand software utilizing CBCT. A line was drawn from the implant shoulder to the first seen point of bone-implant contact and measured. The measurements were noted mesially and distally and the mean value of the marginal bone level was calculated. The change of marginal bone level was calculated.

\section{Bone density around implants}

The Ondemand software utilizing CBCT was used to evaluate the relative radiographic bone density changes.

Bone density was measured using the grey scale of Ondemand software from each side of implant (Mesial, distal, apical). The mean was calculated immediately postoperative and after 6 months, then converted to Hounsfield unit (HU). (14)

\section{Prosthetic phase after follow up phase}

The final prosthesis were placed (porcelain fused to metal) at four months post operatively.

\section{Statistical analysis}

Data were fed to the computer using IBM SPSS software package version 20.0. Quantitative data were described using mean and standard deviation for normally distributed data.

For non-parametric data, comparison between two independent population were done using Mann Whitney test while comparison more than two population were analyzed Kruskal-Wallis to be used. Followed by Post Hoc test "by Tukey method" to detect the level of significant between each two groups.

\section{RESULTS}

The present study included ten patients of both sexes (8 females and 2 males). Their ages ranged between 26-40 years with mean age 34 years. They were selected from the Outpatient Clinic of the Oral and Maxillofacial Surgery Department, Faculty of Dentistry, Alexandria University. Thirteen implants were placed and followed up both clinically and radiographically for 6 months.

In our study, we used basal dental implants with sizes $10 \mathrm{~mm}$ and $12 \mathrm{~mm}$ in length and $4.5 \mathrm{~mm}$ and $3.5 \mathrm{~mm}$ in diameter.

All patients were followed up both clinically and radiographically for six months. Final restorations for all cases were performed after four months from implant placement

All patients had been examined periodically during the follow-up period up to six months. All patients had completed the scheduled follow up.

Healing was uneventful in all cases with no post- operative complications . One case only failed in the 1st week due to infection and wound dehiscence. Other clinical parameters had been recorded during the follow up period such as pain index, implant mobility and primary implant stability.

\section{Clinical evaluation}

\section{1) Pain, tenderness, infection or swelling}

There was pain and tenderness on the first postsurgical days during the follow up period. According to Visual Analogue
Scale (VAS), pain scores ranged between score 2 (which is mild annoying pain) which occurred in 7 patients and score 4 (which is uncomfortable pain) which occurred in 3 patients. Healing was uneventful in all cases with very minimal and unobserved Post-operative edema and discomfort in 7 patients, moderate swelling and edema in 2 patients which subsided spontaneously.

\section{2) Implant stability evaluation}

The implant stability measurement was examined at the time of insertion and 6 months postoperatively using Periotest $M$.

\section{a- Immediate postoperative}

The range of implant stability was -7.9 to +6.2 , the mean value was 0.1 and the median was 0.3 .

\section{b- At 6 months}

The range of implant stability was -8.0 to 3.7 , the mean value was -2.2 and the median was -0.8 .

There was no statistical significant difference regarding stability immediately and after 6 months $(\mathrm{P}>0.05)$. (Table 1$)$

Table (1): Stability immediately and after 6 months.

\begin{tabular}{|l|c|c|c|}
\hline Stability & Immediate & After 6 months & Difference \\
\hline Range & $-7.9-6.2$ & $-8.0-3.7$ & $-14.2-7.6$ \\
Mean & 0.1 & -2.2 & -2.3 \\
SD & 4.5 & 5.0 & 8.2 \\
Median & 0.3 & -0.8 & 0.5 \\
\hline U-test & \multicolumn{3}{|c|}{3.01} \\
P & \multicolumn{3}{|c|}{0.189 N.S. } \\
\hline
\end{tabular}

U-test $=$ Mann Whitney-test

$P=p$ value, significant if $\leq 0.05$

* significant difference

\section{Radiographic evaluation}

\section{Changes in the marginal bone height}

The bone level changes were measured mesially and distally by Ondemand software utilizing CBCT. The bone height was measured immediately post-operative and after 6 months.

Bone height at immediate ranged from 2.1 to $5.8 \mathrm{~mm}$ with mean value $3.8 \mathrm{~mm}$ and median $3.8 \mathrm{~mm}$ while after 6 months ranged from 1.8 to $7.6 \mathrm{~mm}$ with mean value $3.8 \mathrm{~mm}$ and median $2.8 \mathrm{~mm}$.

There was no statistical significant difference regarding bone height immediately and after 6 months ( $\mathrm{P}>0.05$ ). (Table 2)

Table (2): Bone height immediately and after 6 months.

\begin{tabular}{|l|c|c|c|}
\hline Bone height & Immediate & After 6 months & $\begin{array}{c}\text { Mean difference } \\
\text { absolute value }\end{array}$ \\
\hline Range & $2.1-5.8$ & $1.8-7.6$ & -3.0 to 3.8 \\
Mean & 3.8 & 3.8 & 0.0 \\
SD & 1.3 & 2.1 & 1.67 \\
Median & 3.8 & 2.8 & -0.2 \\
\hline U-test & 1.25 \\
P & 0.495 N.S. \\
\hline U-lest= Mann Whitney-/est \\
$P=p$ value, significant if < 0.05 \\
N.S. Not significant
\end{tabular}




\section{Bone density}

Bone density was measured using Ondemand software utilizing CBCT immediately and after 6 months.

The bone density was measured at 9 points placed mesially, distally and apically to the implant and the mean was calculated.

Immediate post-operative it ranged from 295.4 to 1309 hu with mean value 801.4 hu and median 863.4 hu, while after 6 months, the bone density ranged from 300.4 hu to $1548.2 \mathrm{hu}$ with mean value 880 hu and median 967.8 hu.

There was statistical significant difference between immediate and after 6 months $(\mathrm{P} \leq 0.05)$. (Table 3, Figure 4)

Table (3): Bone density at different period of follow up.

\begin{tabular}{|l|c|c|c|}
\hline Bone density & Immediate & After 6 months & Mean percent change \\
\hline Range & 295.4 to 1309.0 & 300.4 to 1548.2 & \\
Mean & 801.4 & 880 & 9.81 \\
SD & 295.3 & 354.1 & 5.95 \\
Median & 863.4 & 967.8 & \\
\hline U & \multicolumn{3}{|c|}{8.98} \\
P & \multicolumn{3}{|c|}{$0.0447^{*}$} \\
\hline \\
U= Mann Whitney test \\
* significant at level 0.05
\end{tabular}

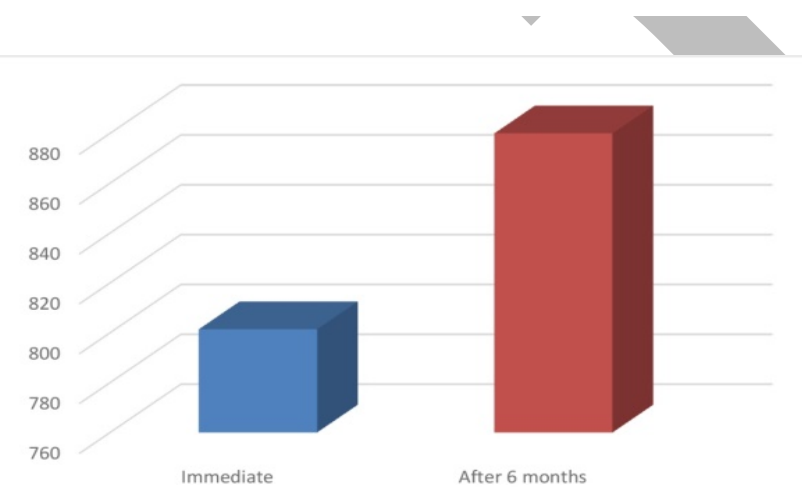

Figure (4): Bone density immediately and after 6 months.

\section{DISCUSSION}

This study was designed to evaluate immediate placement of basal dental implants in the maxillary premolar region. It was conducted on thirteen basal dental implants placed in ten adult patients having maxillary premolar tooth or remaining root indicated for extraction. The patients were selected from the Out Patient Clinic of the Oral \& Maxillofacial Surgery Department, Faculty of Dentistry, Alexandria University.

The selected patients were free from any uncontrolled systemic diseases or conditions that may complicate the surgical procedure or the healing process of the implant. This was following a study performed by Bornstein et al in 2009, (15) where they reviewed whether systemic diseases with/without systemic medications increased the risk of implant failure and therefore diminish the success and survival rates of dental implants. They stated that the level of evidence indicative of absolute and relative contraindications for implant therapy due to systemic diseases is low.

Also, patients suffering from bruxism, heavy smokers, patients receiving chemotherapy or radiotherapy and immunosuppressed patients were excluded from this study. This was following a study performed by Gomez de Diego et al in 2014, (16) where they reviewed the current scientific literature in order to analyze the indications and contraindications of dental implants in medically compromised patients and they concluded that tobacco addiction and head and neck radiotherapy are correlated to a higher loss of dental implants.

Immediate implant placement was selected in this study as there is no need to wait for 4-6 months after extraction for the bone to form and crestal bone loss is found to be less in immediately placed implants rather than delayed placed implants. In addition, with immediate implant placement there is minimal use of surgical drills because the socket is already found except for slight increase of the socket length in an attempt to improve primary stability (17).

The decreased surgical trauma of immediate placement type will decrease the risk of bone necrosis and permit bone remodeling process to occur, i.e. the healing period is rapid and allows the woven bone to be transformed into lamellar bone. Moreover, the natural socket is rich in periodontal cells and matrix, which makes the healing faster and more predictable $(18,19)$.

In our study we used basal implants which are one piece implants in which the implant and the abutment are fused into one single piece (20).

Basal dental implants have smooth surface designs which do not permit bacterial colonization on the implant surfaces which in turn brings down the incidence of peri-implantitis considerably. These implants are uniquely and specifically designed for the sole purpose of gaining anchorage from the basal cortical bone. (11).

Traditional extraction methods have a history of not only producing postoperative pain but also damaging the hard and soft tissues surrounding the tooth. (21) Conventional extraction techniques either elevate the tooth by leveraging against the interproximal bone resulting in damage to the interproximal bone or use of forceps to luxate the tooth from its socket which often results in reshaping of the socket or alveolus. (22) This leads to difficulty in maintaining the socket integrity due to hard tissue damage and thus making future prosthetic replacement difficult.

Also Bortoluzzi et al., Sjögren et al., and Al Khateeb, have conducted studies on postoperative pain in exodontia and observed it as the most common complication (23-25).

Many other complications are also prevalent in exodontia cases due to the conventional methods. Adeyemo et al. (26) have mentioned about presence of alveolitis in $11 \%$ sockets and mild pain in $12 \%$ cases. Bortoluzzi et al. (27) in their study observed an incidence of $0.6 \%$ (2 cases each) for both alveolar infection and dry socket.

To avoid the above mentioned problems, we need to proceed with "atraumatic extraction technique. Atraumatic extraction preserves bone, gingival architecture and allows for immediate implant placement (22). 
In our study, we have used periotome as a means of atraumatic extraction. This instrument helped in removing firm tooth and retained roots without damaging the surrounding thin alveolar plates of bone and minimally lacerating the soft tissue as well. This may aid in providing a completely supportive environment for immediate implant placement. Also periotome seemed to be helpful in maintaining the soft and hard tissue architecture specially in extracting endodontically treated teeth and crown fracture cases.

It aids in removing the tooth without damaging the osseous housing (22).

Marco Cicciù et al. (28) in their study have mentioned that extraction of teeth was not affected by the amount of strength applied or the quality of bone surrounding the tooth but is more technique sensitive. At the same time, it is believed that an excessive force which exceeds expansion of socket results in fracture of alveolus specially in elderly patients in whom bone is dense and sclerotic.

Sharma S (29) found in his study with the maximum number of buccal cortical plate fractures and apical third root fractures occurring in control group as compared to the test group. Periotome provided the opportunity to remove such teeth without reflection of flap and thus avoiding the need of mucoperiosteal flap and exposure of bone. This may be helpful in leaving the shape of extracted socket undisturbed and alveolus intact. In the test group where periotome was used, duration of surgery, frequency and number of analgesics consumed, pain reduction and gingival laceration favoured the use of this instrument for extraction.

Many studies have showed the validity of the immediateloading in the post extractive implants and have guarantee the security of the operative process as long as the stiff fixed protocols are respected. (30-31)

In this study, we used basal dental implants without bone graft or membrane as they were anchored in the cortical basal bone then were loaded immediately without function. On the other hand, knox et al. (32) and Schwartz et al. (33) stated that good primary stability after the insertion of the implant and the respect of the concept of "jumping distance" are very important to the aims of the osseointegration and of the possibility of immediate-loading of a post extractive implant. "Jumping distance" means the distance between the implant surface and the surrounding alveolar walls: if such gap is more than $0.5 \mathrm{~mm}$, you cannot forecast the bone deposit on the surface of the implant without the use of membrane and regenerative procedures.

The technique was developed in response to patients' growing demand for quicker treatment and faster time-toteeth. Ledermann was the first to document successful healing of immediately loaded implants (34), but Schnitman et al. were first to explore the possibility of successfully fixing a partial prosthesis to immediately loaded implants (35). Among the several long-term studies performed since then with 5-10 years' follow-up, high cumulative survival rates, such as around $97 \%$ - $100 \%$ were reported for immediately loaded implants placed in extraction sites for any indication (36). To avoid loading a restoration, the provisional should be out of occlusion.
So, there are many advantages from using basal dental implant in immediate implant placement in maxilla such as saving time and cost. In case of conventional implants associated with bone augmentation or grafting procedures, the total treatment time will be about 6 months to 1 year. In addition to avoidance of a second surgery for implant exposure in order to fix the abutment over the implant. Therefore the dental implant procedure was Fast, Safe \& Painless with unique advantages of immediate loading, avoidance of bone grafting, single piece implantology, basal or cortical bone support, solutions for unfavorable bone situations, extremely low failure rates, virtually no incidence of Peri-implantitis.

We used the Periotest $\mathrm{M}$, it has been one of the methods of determining implant stability and by default a measure of BIC. The Periotest device has the advantage of measuring the implant stability at any stages from implant placement to crown placement and even many years after the crown cementation. Also, it can be used for single piece implants. Truhlar et al. (37), in a comprehensive longitudinal study on the stability of Bone Implant complexes using Periotest values drew up a few pertinent conclusions namely that (1) periotest value (PTV) is influenced by bone quality, (2) PTVs at second stage is the best estimate of the clinically acceptable PTV for a given Bone-Implant complex and (3) A consistent shift toward a positive PTV is a cause for concern with the given BIC and should be viewed as a possible deterioration of the same.

Gomez-Roman G et al. (38) found in their study which associated with specific model samples that the Periotest demonstrated a high degree of reliability and repeatability.

In this study, the mean implant stability value immediately postoperative was $(+0.1)$ indicating acceptable primary stability, while the mean implant stability after 6 months was $(-2.2)$ which indicated a statistically significant increase in implant stability. This acceptable primary stability is attributed to the surgical technique and implant taper. During the surgical preparation of the osteotomy site, a reduced osteotomy diameter was achieved to increase primary stability.

This agreed with O’Sullivan et al., (39) they analyzed the mechanical performance and the primary and secondary stability characteristics of endosseous titanium implants and concluded that the primary stability is affected by the surgical technique and implant taper.

In another study Ayman (40) in 2018 who also used Roott basal dental implants found that the primary stability was high (+0.97) and increased after three months, it was $(-0.83)$.

In this study, thirteen basal dental implants were placed in eleven patients; only one implant failed on the first month (failure rate $7.7 \%$ ). The cause of failure may be attributed to poor oral hygiene and heavy masticatory forces.

\section{CONCLUSION}

Basal dental implants are a reliable option for rehabilitation of posterior maxillary region with consideration to the implant length and thread pitch. Future studies including more patients and longer follow up are needed to assess the long-term success of immediately placed implants. 


\section{CONFLICT OF INTEREST}

The author declare that they have no conflicts of interest.

\section{Acknowledgement}

The author would like to express many thanks for Roott Dental Implant Company.

\section{REFERENCE}

1. Hoffmann O, Bartee BK, Beaumont C, Kasaj A, Deli G, Zafiropoulos GG. Alveolar bone preservation in extraction sockets using non-resorbabledPTFE membranes: a retrospective non-randomized study. J Periodontol. 2008;79:1355-69.

2. Araujo MG, da Silva JCC, de Mendonca AF, Lindhe J. Ridge alterations following grafting of fresh extraction sockets in man. A randomized clinical trial. Clin Oral Implants Res. 2015;26:407-12.

3. Simsek B, Simsek S. Evaluation of success rates of immediate and delayed implants after tooth extraction. Chin Med J. 2003;116:1216-9.

4. Esposito M, Grusovin MG, Tzanetea E, Piattelli A, Worthington HV. Interventions for replacing missing teeth: treatment of perimplantitis. Cochrane Database Syst Rev. 2010:Cd004970.

5. Block MS, Mercante DE, Lirette D, Mohamed W, Ryser M, Castellon P. Prospective evaluation of immediate and delayed provisional single tooth restorations. J Oral Maxillofac Surg. 2009;67:89-107.

6. Chiapasco M, Zaniboni M. Clinical outcomes of GBR procedures to correct peri-implant dehiscences and fenestrations: A systematic review. Clin Oral Implants Res. 2009;20:113-23.

7. Jaffin RA, Kolesar M, Kumar A, Ishikawa S, Fiorellini J. The radiographic bone loss pattern adjacent to immediately placed, immediately loaded implants. Int J Oral Maxillofac Implants. 2007; 22:187-94.

8. Tadi DP, Pinisetti S, Gujjalapudi M, Kakaraparthi S, Kolasani B, Vadapalli SH. Evaluation of initial stability and crestal bone loss in immediate implant placement: An in vivo study. J Int Soc Prev Community Dent 2014;4:139-44.

9. Yadav R, Sangur R, Mahajan T, Rajanikant A, Singh N, Singh R. An Alternative to Conventional Dental Implants: Basal Implants. Rama Univ J Dent Sci 2015;2:22-8.

10. Sharma R, Prakash J, Anand D, Hasti A. Basal implants - an alternate treatment modality for atrophied ridges. IJRID 2016;6:60-72.

11. http: trate .com / implants / en/ basal .

12. Rahul S, Jai P, Dhruv A, Anurag H. Basal implants- An alternate treatment modality for atrophied ridges. IJRID. 2016;6:60-72.

13. Drago CJ. A prospective study to assess osseointegration of dental endosseous implants with the Periotest instrument. Int J Oral Maxillofac Implants. 2000;15:389-95.

14. Kersten P, Küçükdeveci AA, Tennant A. The use of the Visual Analogue Scale (VAS) in rehabilitation outcomes. J Rehabil Med. 2012;44:609-10.
15. Khurram A, Chee LF, Peng LL, Tho CY, Wei WC, Baig MR. Implant placement in extraction sockets: A short review of the literature and presentation of a series of three cases. J Oral Implantol. 2008;34:97-106.

16. Bornstein MM, Cionca N, Mombelli A. Systemic conditions and treatments as risks for implant therapy. Int J Oral Maxillofac Implants. 2009;24:12-27.

17. Gómez-de Diego R, Mang-de la Rosa Mdel R, RomeroPérez MJ, Cutando-Soriano A, López-ValverdeCenteno A. Indications and contraindications of dental implants in medically compromised patients: Med Oral Patol Oral Cir Bucal. 2014;19:e483-9.

18. Barzilay I, Graser GN, Iranpour B. Immediate implantation of pure titanium implant into an extraction socket: Report of a pilot procedure. Int J Oral Maxillofac Implants.1991;6:277-84.

19. Ericsson I. Early functional loading of branemark dental implants: 5-years clinical follow up study. Clin Implant Dent Relat Res.2000;2:70-7.

20. Hansson HA, Albrektsson T, Branemark PI. Structural aspects of the interface between tissue and titanium implants. J Prosth Dent.1983;50:108-13.

21. Pozzi A, Gallelli L. Pain management for dentists: the role of ibuprofen. Ann Stomatol. 2011;2:3-24.

22. Levitt D. Atraumatic extraction and root retrieval using the periotome: a precursor to immediate placement of dental implants. Dent Today. 2001;20:53-7.

23. Bortoluzzi MC, Manfro AR, Nodari RJ, JrandPresta AA. Predictive variables for postoperative pain after 520 consecutive dental extraction surgeries. Gen Dent. 2012;60:58-63.

24. Sjögren A, Arnrup K, Jensen C, Knutsson I, Huggare J. Pain and fear in connection to orthodontic extractions of deciduous canines. Int J Paediatr Dent. 2010;20:193-200.

25. Al-Khateeb TH. Pain experience after simple tooth extraction. J Oral Maxillofac Surg. 2008;66:911-7.

26. Adeyemo WL, Ladeinde AL, Ogunlewe MO. Clinical evaluation of post extraction site wound healing. J Contemp Dent Pract. 2006;7:40-9.

27. Bortoluzzi MC, Manfro R, De Déa BE, Dutra TC. Incidence of dry socket, alveolar infection, and postoperative pain following the extraction of erupted teeth. J Contemp Dent Pract. 2010;11:33-40.

28. Cicciù $M$, Bramanti $E$, Signorino $F$, Cicciù $A$, Sortino $F$. Experimental study on strength evaluation applied for teeth extraction: an in vivo study. Open Dent J 2013;7:20-6

29. Sharma SD1, Vidya B2, Alexander M3, Deshmukh S4. Periotome as an Aid to Atraumatic Extraction: A Comparative Double Blind Randomized Controlled Trial. J Maxillofac Oral Surg 2015;14:611-5.

30. Chaushu G, Chaushu S, Tzohar A, Dayan D. Immediate loading of single tooth implants: immediate versus nonimmediate implantation. A case report. Int J Oral Maxillofac Implants 2001;16:267-72.

31. Hui E, Chow J, Li D, Liu J, Wat P, Law H. Immediate provisional for single-tooth implant replacement with Branemark System: preliminary report. Clin Implant Dent Relat Res 2001; 3:79-86. 
32. Knox R, Caudill R, Meffert R. Histologic evaluation of dental endosseous implants placed in surgically created extraction defects. Int $\mathrm{J}$ Periodontics Restorative Dent 1991;11:364-75.

33. Schwartz-Arad D, Chaushu G. Immediate implant placement: a procedure without incisions. J Periodontol 1998;69:743-50.

34. Ledermann P. Bar-prosthetic management of the edentulous mandible by means of plasma-coated implantation with titanium screws (In German). Deutsche Zahna"rztlicheZeitschrift. 1979; 34:907-11.

35. Schnitman PA, Wohrle PS, Rubenstein JE. Immediate fixed interim prostheses supported by two-stage threaded implants: methodology and results. Int J Oral Implantol. 1990; 16:96-105.

36. Mura P. Immediate Loading of Tapered Implants Placed in Postextraction Sockets: Retrospective Analysis of the 5-Year Clinical Outcome. Clin Implant Dent Relat Res. 2012;14:565-74.
37. Truhlar RS, Morris HF, Ochi S. Stability of the boneimplant complex. Results

of longitudinal testing to 60 months with the periotest devices on endosseous dental implants. Ann Periodontal. 2000; 5:42-55.

38. Gomez-Roman G, Lukas D. Influence of the implant abutment on the

Periotest value: an in vivo study. Quintessence Int 2001;32:797-9.

39. O'Sullivan D, Sennerby L, Meredith M. Influence of implant taper on the primary and secondary stability of osseointegrated titanium implants. Clin Oral Implants Res. 2004; 15:474-80.

40. Elsayed A, Eldibany R. Placement of the basal dental implants in the edentulous posterior maxillary region: A clinical and radiographic study. M.Sc. Thesis. Department of Oral and Maxillofacial Surgery, Faculty of Dentistry, Alexandria University, Egypt. 2018.

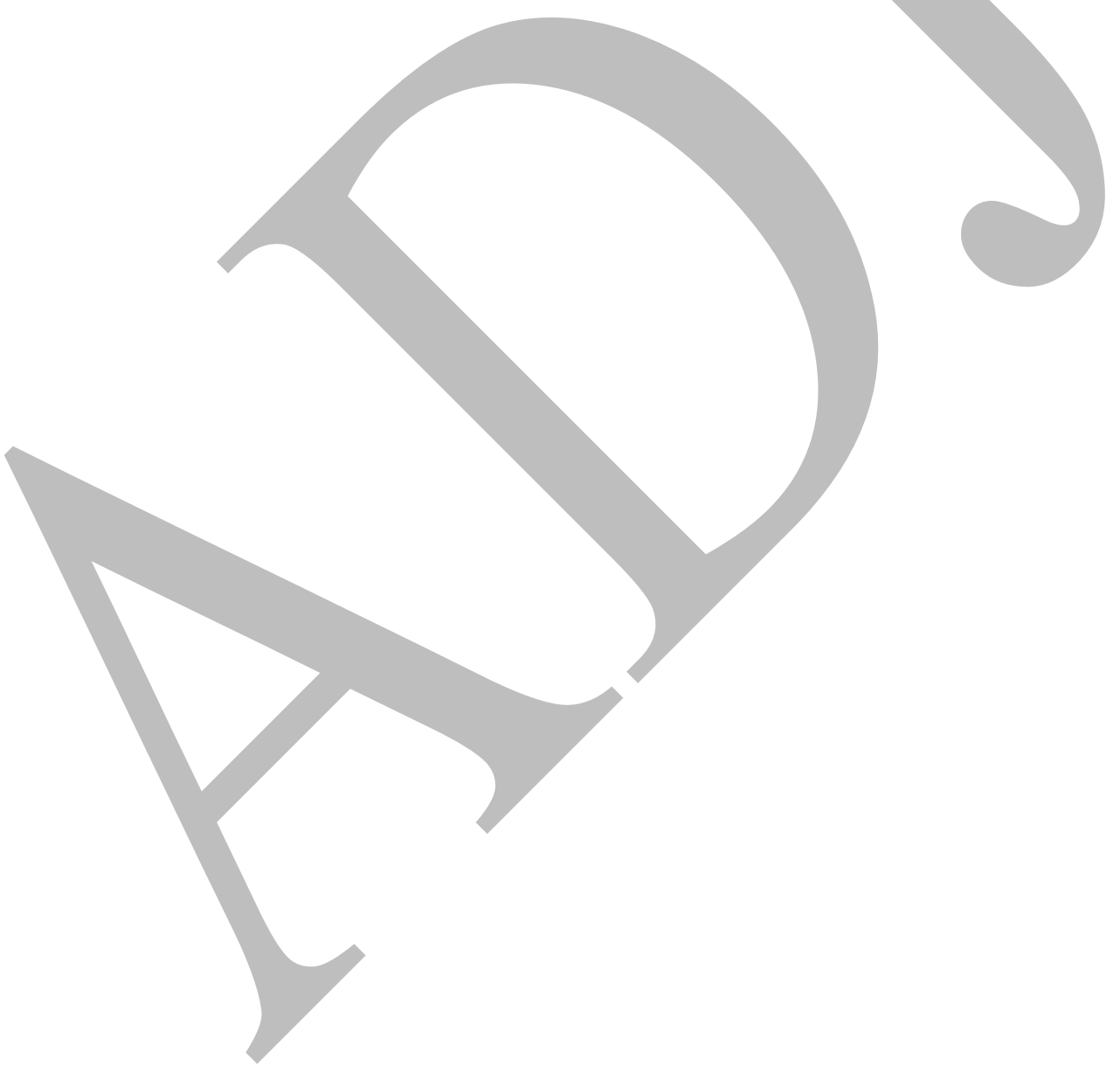

